\title{
Democratic Participation through Crocheted Memes
}

\author{
Ella Taylor-Smith \\ Edinburgh Napier University \\ School of Computing \\ Edinburgh, UK \\ e.taylor-smith@napier.ac.uk
}

\author{
Colin F. Smith \\ Edinburgh Napier University \\ School of Computing \\ Edinburgh, UK \\ cf.smith@napier.ac.uk
}

\author{
Michael Smyth \\ Edinburgh Napier University \\ School of Computing \\ Edinburgh, UK \\ m.smyth@napier.ac.uk
}

\begin{abstract}
In a UK city, various crocheted protest banners have appeared, containing political statements concerning planned developments in their locations. Photos of these banners are shared across social media, raising awareness and potentially playing a role in local campaigns. This study explored peoples' perceptions of these banners as photos within social media interactions, focusing on how associated emotions or values influenced their views of the campaigns. The aim was to increase understanding of the impact of images within social media, both on engagement with offline situations and on propensity to forward (e.g., retweet). People who had posted or shared pictures of the banners were interviewed. The study is framed by considering the banners - in both yarn format and digital photos-as memes. This situates the study within contemporary research into public participation online, especially the ways in which information, disinformation, and emotions travel across social media, and the influence of this on democracy. This article uses diverse definitions of memes to draw out insights from the interview data, about participants' engagement with the banners and with the corresponding local issues, campaigns, and ultimately democracy. Interviewees were engaged by both the medium of the offline banners and the text embroidered onto them. In terms of the medium, the process of crochet was most important-indicating the time invested and encompassing memories. Interviewees were most engaged by banners concerning places they passed every day, though they did not agree with all the banners' messages.
\end{abstract}

\section{CCS CONCEPTS}

Permission to make digital or hard copies of all or part of this work for personal or classroom use is granted without fee provided that copies are not made or distributed for profit or commercial advantage and that copies bear this notice and the full citation on the first page. Copyrights for components of this work owned by others than ACM must be honored. Abstracting with credit is permitted. To copy otherwise, or republish, to post on servers or to redistribute to lists, requires prior specific permission and/or a fee. Request permissions from Permissions@acm.org.

SMSociety '18, July 18-20, 2018, Copenhagen, Denmark (C) 2018 Association for Computing Machinery. ACM ISBN 978-1-4503-6334-1/18/07 ..\$15.00 https://doi.org/10.1145/3217804.3217910
- Human-centered computing $\rightarrow$ Social media

\section{KEYWORDS}

Meme, social media, democracy, place, yarn, emotion

\section{INTRODUCTION}

Early ideas about online democracy envisaged a virtual public sphere, where citizens could participate and potentially share governance through deliberation $[9,21$, 36]. Over time, it became clear that this was only an effective method of participation for a small subset of people, matching those who were already democratically active and influential [15, 21, 22]. More recently, the parallel rise of social media and smartphones with cameras enabled people with the appropriate technology to easily share images, video and audio files, opening up a whole new world of expression online, potentially including participation in democracy [e.g., 26, 33]. In their global, anthropological research into the uses and consequences of social media, Miller et al. find "the expanded potential for people with low levels of literacy now to participate in social media" [25]. Gil de Zúñiga, Barnidge and Scherman [16] find, in the U.S. context, that good social media capital can positively influence offline political participation.

Hoffmann and Lutz's overview of research into the relationship between Internet use and political participation [18] parallels the narrative outlined above [i.e., 9, 21, 22, 36], but also finds reasonable evidence for the positive (though weak) effect of Internet use on political participation. Further, they suggest ways in which social media facilitate publishing and sharing political content, finding likeminded users and coordinating groups. While Hoffman and Lutz describe these as potential advantages for young citizens, these could also facilitate participation for social media users of all ages. They also describe potential hindrances to engagement, such as impression management, leading to self-censorship.

Social media have come to be associated with heavier threats to democratic engagement than young citizens' selfcensorship; Wardle and Derakhshan [34] alert us to "information pollution at a global scale" as people appropriate social media technology to spread "misinformation," "dis-information," and "mal-information" to 
disrupt positive democratic discourse, "specifically to sow mistrust and confusion and to sharpen existing sociocultural divisions using nationalistic, ethnic, racial and religious tensions." Marwick and Lewis [23] investigate these activities in the context of news-i.e., as "media manipulation", describing how right-wing groups have developed their skills in gaining attention online, leveraging "both the techniques of participatory culture and the affordances of social media" to insert their ideas (or at least references to their ideas) into mainstream media, and to attack, for example, women and those advocating social equity.

Internet memes have been identified as ways for diverse people to express their ideas about values and events [11, 28, 32]; for example, as elements of participatory culture [19], or protest [26]. Miller et al. identify "the ability of people with limited self-confidence to find new ways of expressing sentiments indirectly through memes" [25]. Memes can link the personal and political, enabling citizens to participate in political campaigns, sharing their personal perspectives and maintaining their individuality [32]. Memes enable people to share their own (and each other's) experiences via social media, potentially building campaigns through connective action [2].

These characteristics of memes have also been used to have a negative impact on democracy. Marwick and Lewis [23] highlight their use as propaganda by neo-Nazi groups, who release collections of images weekly, so that at least some variants are likely to be shared, gaining more impact when spread through personal ties. Marwick and Lewis describe "deeply racist" memes, some "explicitly evoke Nazi imagery," plus milder images, "intended to work as 'gateway drugs' to the more extreme elements of alt-right ideology."

In this study, the concept of an Internet meme is used as a framework to explore people's participation in democracy, as they share photos of crocheted protest banners on social media. The study was undertaken to gain greater understanding of the role of images within social media and, through this, into democratic participationfocusing on the materiality of the offline banner to illuminate the links between online and offline experience. The study also provides evidence of positive democratic behaviour on contemporary social media. It does not describe unanimous agreement on local issues, nor much success in changing their city council's development priorities. However, it describes and analyses the use of social media to share positive values about local spaces and marginalised people, such as refugees (Figure 1).

The research is inspired by the hypothesis that people who interact with the crocheted memes on social media are influenced by the material of the offline banners (wool/yarn) in their interpretation of the messages and in their reactions to the banners and images on social media.
Semi-structured interviews with people who have tweeted or retweeted images of the banners explore this engagement, including the values and emotions participants experience in their interactions with the banners.

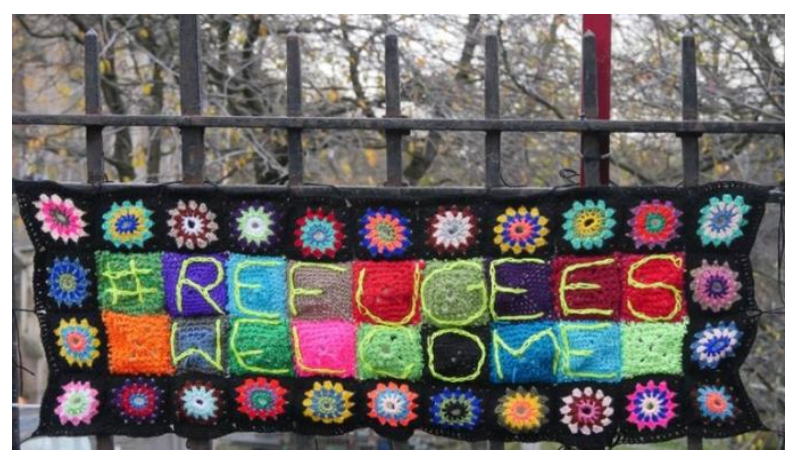

Figure 1: Refugees Welcome banner $($ F Fatblackcatspaw.

\section{INTERNET MEMES}

\subsection{Literature review}

The term meme, used in this context to mean Internet meme, is contested and evolving. This study takes an inclusive view of the term, using its various assigned attributes to explore the engagement of social media users in a UK city with photos of crocheted banners protesting local developments.

Dawkins coined the term meme to propose a cultural parallel to the gene: "a unit of cultural transmission, or a unit of imitation" [14]. The meme appears to have agency, propagating itself through our brains and actions, but, for Dawkins, this idea of internal purpose is really only a metaphor. He does not concern himself with the paradox that the impetus to share comes entirely from the meme, whereas the action is performed by humans. Carey [8] seems to reflect Dawkins' blurring of the boundaries between biology and culture in his assertion that "media and communication are not merely instruments of will and purpose but definite forms of life: organisms, so to say, that reproduce in miniature the contradictions in our thought, action, and social relations." Carey's emphasis on the symbolic function of communication is useful here, as the material nature and traditional production of the offline banners potentially influence their impact in digital formats.

Godwin applied the term meme to processes of Internet culture-specifically, the propensity of Usenet arguments to deteriorate into accusations of Nazism [17]. By naming the phenomenon this way, he hoped to create a countermeme that would inhibit or counteract the process. As the Internet became more densely populated and Web 2.0 platforms, such as YouTube and Facebook, made it easier for people to share content, writers used the biological 
metaphors of viral and meme to investigate the type of content that was extensively shared [7]. Jenkins focused on the content's spreadability [19]. In this conception, the meme, as in Dawkins' metaphor, acquires an internal purpose - to spread itself - and researchers investigate the characteristics and contexts that facilitate this.

boyd provides a birth narrative of classic picture-andtext Internet memes [6], where meme culture arises from the ephemeral nature of 4chan image boards in 2003 [cf. 29]. The boards' anonymous posters used certain images with text (memes) as cultural artefacts of their community: while each image and post was ephemeral (unarchived), it could be re-posted with modifications [6]. Rules evolved around the acceptable contents, style, and use of these memes, enabling the images-and continuous conflict around the images - to embody this community of anonymous people [29]. Bowker and Star [5] describe the importance of objects in communities of practice, where becoming part of a community involves understanding that community's objects, including their tools, symbols, texts, processes, routines. New group members learn each object's importance and appropriate use; the meaning of each object depends on the context, including the perspective of the group. Pearce describes this in terms of memes' sharedness, becoming "a powerful performative act of both group identification and differentiation" [31]. Julien [20] understands the rules governing memes as a feature of a digitally-oriented field, after Bourdieu [4]: understanding and following the rules indicates that the meme-poster shares the appropriate cultural background (habitus) for the online context and should be treated with respect.

While boyd's 4chan example [6] illustrates the essential role of memes in creating ingroups and outgroups, 4chan can neither be credited with inventing Internet memes nor allowed to define meme characteristics beyond their own community. In the interviews at the centre of this study, one of the participants alerted the researcher to the contemporary role of the website Make a Meme.org in colonising the concept: the website's users can choose a square picture, add text to the top and bottom, and then share their meme on social media. In this way, the website promotes a default format.

For Shifman, the defining characteristic is that individual memes are part of collections: "a group of digital items sharing common characteristics of content, form, and/or stance" [32]. This is illustrated in Milner's [26] account of the use of memes in the Occupy Wall Street campaign, where people add their own caption to certain images or re-create images, for example, by holding up handwritten signs. While images are recognisably part of a collection of similar images associated with the campaign, people are able to personalise the images. Others can create images that share these formats, but critique or ridicule the campaign.

In contemporary usage, the biological metaphor $[3,14]$ may be more or less important to identifying memes, while rules about format or content tend to be culturally local and fleeting. People in Miller et al.'s studies use the term meme to describe pictures that they did not take themselves, especially images and video which include text [e.g., 24, 25]. Images that Miller et al.'s participants describe as memes broadly reflect the purpose of creating ingroups through promoting certain moral or philosophical outlooks, but they are as likely to resemble the motivational posters of the 1970s as the rigid aesthetics of 4chan memes.

Davison [13] notes that memes are typically jokes. While this does not hold for the religious, moral, and philosophical memes encountered by Costa in Turkey [11] and Nicolescu in Southeast Italy [28], there is evidently some overlap in terms of purpose, as humorous memes often carry a moral stance [e.g., 25]. Miller and Sinanan [24] note this "combination of humour, moralising and "truth"; for example, where meme catchphrases are essentially used to highlight wrongdoing.

\subsection{Five Characteristics of Internet Memes}

From this overview of the literature, five prominent characteristics of memes, related to both their aesthetics and use, were identified:

1. spreadability - people share the meme;

2. memes are used to identify people as ingroup or outgroup;

3. memes are used to share and promote personal and/or community values;

4. aesthetically, memes are recognisably part of a collection of media;

5. and their format is a combination of image with text.

These characteristics are used to define memes and explore their use in the articles referenced above, though, of course, not all memes share all of these characteristics. For example, video memes are not generally combinations of image with text. This study used these five characteristics of memes to explore people's reactions as they interacted with images of a very specific type of media - the crocheted local protest banner - on social media. The aim is not to judge the banners or photos according to whether they resemble memes, but to use these characteristics to understand their role in democratic participation. Sharing images on social media is a rather different type of democratic engagement to taking part in an online discussion or signing an e-petition. This type of engagement, where social media posts are centred on images, has been investigated by people researching memes in the context of activism [e.g., 26, 27, 32]. So, it is hoped 
that this parallel will illuminate the motivations and activities of our participants.

People who had posted or retweeted images of the crocheted protest banners were interviewed and the characteristics of memes, as identified above, framed the thematic analysis of the interview data.

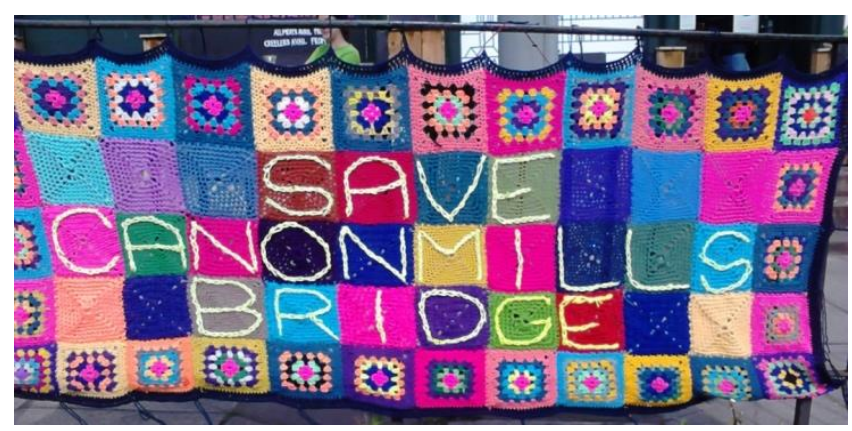

Figure 2: A crocheted protest banner in situ.

\section{METHODOLOGY}

The banners at the centre of this study are created out of crocheted squares, with letters sewn onto the squares (e.g., see Figures 1 and 2). The messages on the banners primarily concern planned local developments. For example, the Save Canonmills Bridge banner (Figure 2), protested against the planned destruction of historic, lowrise, buildings on the bridge, in order to replace them with a multi-story residential block. Across the city, specific banners were attached to street furniture, such as railings, scaffolding, or tree-guards. Apart from the banners welcoming refugees, each banner protested a planned development in its immediate vicinity.

Publicly-posted digital photos of the banners were identified online through an iterative process of searching (via Google and Twitter) for the text of any known banners, starting with those that had been seen offline or online within prominent local campaigns. More banners were identified by looking through the public online presences (e.g., Twitter and blogs) of people who had posted images of the banners on social media. Further banners were identified by searching for the terms "[UK city]" and "Yarn" (via Google and Twitter). The search was primarily restricted to Twitter, in order to focus on public content. When a post containing an image of a banner was found, the researcher followed all the accounts that had retweeted or commented on the image. Where possible, the researcher contacted each account's owner, for example via email if the Twitter account linked to a blog with an email address, or via Twitter message, if the account's owner reciprocated the researcher's follow. This was an iterative process, as banners and tweets were identified through following people's Twitter accounts and also through the interviews.
The searches and interviews led to a collection of images of about 20 crocheted banners. Some images were message duplicates, where the same message appeared on more than one (different) banner. The messages mostly concerned local developments, including several large developments in which historic areas of the city would be commercialised, losing landmark buildings and public ownership of space. Several concerned a controversial public transport initiative: the re-introduction of trams. One concerned the loss of a popular public sculpture (the Pigeons), though this was also associated with the city tram project. Some banners welcomed refugees (e.g., Figure 1).

About 60 social media accounts were identified and contact details were found for 23 of these accounts. Two accounts were rejected because the owner was known to the researcher. Messages were sent to the other 21 accounts, either via email or Twitter message. Ten interviews have been conducted: six women; four men; six people in their 30 s or 40 s, one person a little younger, and three older. All participants lived and worked in the UK city where the banners were seen. Interviews were semistructured, with around ten questions, concerning: the participants' experience of seeing one or more of the banners; choosing to post or retweet images; their awareness of any associated campaigns and any subsequent involvement; their emotional reactions; and, finally, their assessment of whether the images could reasonably be described as memes. The interview protocol is provided as an appendix to this paper. Interviews were conducted faceto-face, audio-recorded, and transcribed. Most interviews took twenty-minutes and many participants commented that they found the experience interesting, even enjoyable. Participants were interviewed in 2017; the social media posts and retweets had occurred over the preceding two years, except for posts associated with the banner created by Interviewee 4 in 2014.

University ethics procedures were followed: the researchers went through a checklist to identify any issues and necessary actions and this was approved by the ethics committee. The actions identified concerned: informing participants, anonymising participants and their posts (as far as possible), and treating participants and other people within the research narrative with respect. Interviewees were asked to sign an informed consent form, describing the research aims and method, the anonymisation and potential use of the interview data, and their rights within the project. This form was provided in advance of the interview. Some people had posted photos in tweets which participants forwarded, but declined to be interviewed. Their permission, and that of interviewees who had provided photos, was sought each time one of these photos was used in a paper or presentation about the research. The research methodology involved following potential participants on social media and they often reciprocated. 
This created relationships that exist beyond the boundaries of the study; some follows persist and online networks overlap. Beaulieu and Estalella [1] describe this in terms of contiguity of the research field with the professional and personal (and also traceability). This context illustrates the importance of treating participants ethically and with respect throughout the research process, from identifying potential participants to publishing and beyond.

The interview transcripts were analysed thematically, using the five characteristics of memes identified above. The findings from this analysis provide useful insights into contemporary democratic participation online, especially within the current negative discourses around social media and democracy, fake news, information pollution, and the attention economy [6, 23, 34].

\section{FINDINGS}

These findings explore the interviewees' engagement with social media posts centred on images of crocheted banners which criticised local developments. The findings are organised according to the characteristics of memes outlined above, because, in previous research, memes have been a prominent focus of how images are used online, especially in the context of democracy. Memes can provide ways for diverse people to become involved in issues and campaigns, through sharing, and potentially personalising, political messages [2, 25, 26, 32]. This approach does not imply that the participants considered these banners, images, or posts to be memes. Their perspectives on this are also explored and reported below. The interviewees' understanding and definitions of meme are particularly interesting, both in terms of tracing the term's development and exploring how widely this potentially specialist concept is understood.

\subsection{Spreadability}

The first important characteristic of memes, identified above, is their spreadability-something within the meme makes people share it. Interviewees were asked about why they had retweeted posts containing photos of the banners or photographed the banners and posted them on public social media (mostly Twitter). Participants engaged with the banners, or posts about the banners, because of the messages on the banners, the banners' aesthetics, and because they had been crocheted. For example, interviewees posted and retweeted images of a banner referring to the loss of a local sculpture: "because I completely agree with that message" (Interviewee 1); "I've probably ranted about that myself" (Interviewee 2).

Participants experienced tension when they respected a banner's appearance and creation, but disagreed with the text embroidered onto the crocheted squares. Conversely, some interviewees accepted the message because of the banners' medium or method, either retweeting on the assumption that the text was correct or being inspired to find out more about the situation (the planned development and any associated campaigns): "I might give that more weight automatically as being not misleading because of the medium maybe" (Interviewee 6).

\subsection{Identifying as ingroup or outgroup}

The second characteristic of memes is the way they can be used to identify people as part of a group or community, or as an outsider. Each banner referred to a local development and had been hung in a place affected, or about to be affected, by this change. Thus the strongest community feelings were local reactions to the place they strongly identified with and felt some ownership of, especially locations they passed every day, with much-loved features. One interviewee had created a local protest banner largely to "boost the morale" of the relevant campaign group; it also spoke directly to the local community-publicising that people could legally walk across the contested land. The text on the banner read "Welcome to [this estate]", further functioning as a correction to the developers" "no entry" sign.

In general, the banners inspired feelings of community in the interviewees: "a little bit of communityness" (Interviewee 4). This came from the banners' association with local places, combined with the work contributed (anonymously) by the creators and the warmth of the medium (wool, though presumably acrylic). However, participants were frustrated when banners claimed to speak for them, but they disagreed, especially when one banner declared that a specific district of the city "says no to trams" (concerning a proposed extension of the controversial transport development). For example, Interviewee 1 questioned the anonymous creator: "Who are you to take on the right to speak for all people of [this district]?" Crafters were another important community, especially those involved in knitting and crochet. These people felt a certain pride in seeing their craft out there, trying to make a positive difference. This group also experienced conflicting emotions when they disagreed with a banner's message or tone.

\subsection{Sharing or promoting values}

Another way to understand how memes can tap into feelings of community and alienate outsiders is to observe people creating and sharing memes in order to promote values, whether advertising their personal values or encouraging members of their community to conform to values $[11,24,28]$. The important factors here were the embroidered texts and the time and work put into creating the banners. Participants shared images of individual banners that they agreed with. On forwarding an image of a banner reading "Refugees Welcome", Interviewee 3 said: "I want the people that follow me on social media to know 
where I stand on, you know, refugees coming into the country." This is interesting in light of Hoffmann and Lutz' [18] work on self-censorship on social media: the interviewee's expressed desire to advertise a potentially controversial viewpoint. Several also understood the banners collectively, as an attempt to push-back against the city council, which seemed to favour commercial interests over those of local people and historic buildings: "a lot of them tend to be about conservation and about valuing people over developments, and anti-corporate" (Interviewee 8); "It's speaking of changing values" (Interviewee 6).

The medium and creation process tapped into people's values, for example resonating with their experience of family and faith: "They possibly sort of tap into memories, which I guess might influence emotions, about my family and the women in my family and their use of knitting and sewing and how that was an important every day part of their lives; and of my childhood maybe more than of my adult life" (Interviewee 7); "It's made of traditional skills and simple materials. I find that a nice value as part of my [religion]" (Interviewee 5).

Interviewees also appreciated the banners as a powerful, gentle, creative way to do democracy: "What the banners kind of convey, to me anyway, is a kind of progressive activism-activism that's not destructive or negative, just shouting. It's more like a kind of quiet conversation with people. And people perhaps pay it a bit more attention" (Interviewee 4). These ideas echoed Corbett's [10] advocacy of Craftivism, though no one mentioned her work directly; one interviewee introduced the term, unaware it was already in circulation. The creators' work added value (emotional and political weight) to the banners' messages: "somebody's put a lot of effort into it [...] there's someone who cares a lot about this" (Interviewee 2); "It's also passionate, because there would have been a lot of time put into that. Somebody feels passionate about this issue" (Interviewee 5).

\subsection{Format: Variations on a Theme; Text and Image}

The final characteristics of memes identified above concern their format. Individual images (or videos, etc.) are variations on a theme: aesthetically, memes are recognisably part of a collection of media [32]. Interviewee 1 noted: "the way in which these ones all have that same shape and, you know, they're very samey. I can see that sense of being a meme." The study has found references to over twenty local banners which follow the format of: crocheted squares, sewn together in a grid pattern, with letters sewn onto individual squares in order to spell out messages - mostly concerning the immediate locale of the banner. The creator of one of the banners has been interviewed; the creator of the others remains anonymous to the researcher, but is known by at least two of the interviewees-apparently an individual, rather than a group. Interviewees also mentioned related activities within and beyond the city, including collective yarnbombing and the Wool against Weapons banner, which grew to seven miles and has now been separated and redistributed as blankets [35].

\subsection{Are They Memes?}

Interviewees were asked whether or not they knew the term "meme" and if they thought these images were memes. Four interviewees would not call the images memes, mostly because they lacked the virality of memes: they had not spread far enough or fast enough. One person felt that the integrated format of words and background was a problem: for a meme, "somebody takes different things and puts them together" (Interviewee 4). Two participants pleaded their lack of comprehension of the term; one would not use the term because "it's not in my vocabulary" (Interviewee 8); another because their understanding of it was too vague (Interviewee 9).

Three interviewees would apply the term in this context and one more could see its potential. Like the first four, these interviewees identified memes as ideas which spread, as well as image/text formats online: "a cultural brainworm, $[\ldots]$ something that gets shared and worms into the social consciousness" (Interviewee 2); "there's an attempt to create that idea in people's mind in the hope that it will go on to have some effects on actual planning policy" (Interviewee 5). One provided a vivid conceptualisation: "the little kind of micro thing [...] that can be shared through social media [...] kind of a big concept in a tiny basket" (Interviewee 3).

Most interviewees had a good understanding of the term, including both its origins with Dawkins [14] and its Internet transformation into a visual format: "People now seem to be talking about it as a picture with a statement underneath. [...] I originally thought that it was about ideas spreading" (Interviewee 8). Of the four interviewees who accepted the appropriateness of the term in this context, two (who focused on memes as ideas) would be prepared to consider the offline banners as memes: "It was a physical meme, but then, by act of photographing and sticking it on Twitter, I guess it could have become a digital meme as well. [...] If enough people had taken a photo of it, it maybe could have got to a kind of meme level. But yeah, if you remove the digitalness, I think it could be a physical meme-something that got talked about in the pub" (Interviewee 2). This comment reveals the tension between simultaneously understanding memes as ideas and understanding them as messages combined with images. These two understandings would appear consecutively in a timeline describing popular use of the term, especially as it moves from Dawkins' memes to Internet memes. However, 
for several interviewees, both meanings remained active at some level.

This study uses ideas about Internet memes to explore people's engagement in democracy through images on social media. One interviewee described the unhelpful use of memes in online discussions as "like a lazy way of eating"-where people might previously have presented an argument, they "will now throw out a meme as though that's an answer to something. [...] It's like the fast food of thought $[\ldots]$ you could actually have a nice meal: i.e., you could actually say what you think, or you just have a meme" (Interviewee 6). He was enthusiastic about the crocheted banners as an engaging way to share information and unwilling to call the images memes: "maybe on the whole I'm more negative than positive view of memes as I know them. I don't necessarily know if that's why I don't regard [these banners] as memes" (Interviewee 6).

\section{DISCUSSION AND CONCLUSIONS}

The crocheted protest banners had really engaged the interviewees, whether they encountered them on or offline. Participants gave up their time to be interviewed, even if the interview request concerned one retweet from over a year ago. They were engaged because of the aesthetics of the banners and images (for example, their bright colours), the obvious time and effort contributed by their creators, the associations of the fabric (wool/yarn), and the personal resonance of the messages sewn onto the crocheted squares. The interview data is rich with detail about how these factors entwine and influence the participants - even to inspire them to find out more about the issue or campaign. The research began with the hypothesis that people who interact with the knitted memes on social media are influenced by the material of the offline banners (wool/yarn) in their interpretation of the messages and in their reactions to the banners and images on social media. Participants were engaged by the medium of the banners, especially those who identified with knitting, yarnbombing and craft communities, as well as those who admired the combined simplicity and skill of the medium and process. The process was also a link to family and the past: "It's got that feeling to it as well-your granny's done it" (Interviewee 9). Participants were most engaged by the process of creating the banners: the time contributed to crochet the banners became a value of the banners, encapsulating the assumed importance of each banner's message to the banner's creator. Participants were also engaged by the banners' attractive appearance, especially their bright colours. These factors together (the creators' time, the traditional process, the attractive appearance) did influence the participants' perceptions of the banners' messages and their interactions. However, participants' opinions of the messages were more important. The strongest emotional reactions were associated with messages that resonated deeply or with messages they disagreed with. Issues of community and place were also integral to these strong reactions. Three interviewees revealed their involvement with yarnbombing and a further two were involved in crafting. This relationship did not have a consistent impact on their appreciation of the banners' messages. Where interviewees disagreed with the message, either its import or phrasing, their association with yarnbombing or crafting seemed to cause a certain tension, but did not change their opinions.

The participants were fairly evenly divided in their willingness to designate the banners or images as memes: four willing, four refusing, and two abstaining. Some approved or rejected the term due to the banners' format, but more due to the lack of virality, echoing questions about whether memes are defined by their internal purpose, their aesthetic characteristics and context, or the speed and success of their spread.

The thematic analysis of this interview data used a framework based on the concept of Internet memes, especially as they may be used within protests and campaigns and, more generally, to share values. This analysis has provided a useful entrance to this dataset, especially to exploring the relationship between the medium and appearance of the banners and the messages they contain. The study provides insights to the way work and values traverse the threshold between on and offline, as the work of the banners' creators adds to their online value and, in some cases, their credibility. The banners also seem to inspire feelings of community, in terms of ingroups or outgroups, especially provoking lasting frustration when they claimed to speak for a local community who do not necessarily agree with the embroidered statements.

While the meme framework provided a useful introduction to participants' engagements with the banners, there is more detail in the data about how this engagement linked into people's experience of local urban places and into specific campaigns against building and transport developments. Questions also build around the threshold between online and offline, continually traversed by participants as they experience and consider these banners and posts, developments and campaigns. Because the original concept of a meme concept centres on the meme as something which propagates itself [14], it is of limited help in describing the perspective of the banners' creators, even as their contributed time is an essential characteristic of the images. The one creator interviewed, Interviewee 4, was predominantly concerned to cheer up local campaigners, while maintaining the mystique of anonymity. However, the creator(s) of other similar banners may be more interested in their trajectory across social media and any influence gained that way.

The next steps of the project include interviewing people who were involved in the campaigns about their 
perceptions of the influence of the banners. The next layer of data analysis will attempt to uncover more detail about the connections between the online and offline lives of the banners and the corresponding influence of seeing images of the banners on social media on taking effective action to protect local environments from destruction and public spaces from commercialisation.

Papacharissi's work [e.g., 30] highlights the role of emotion in the relationship between Internet posts and democratic participation; emotional engagement is an essential component of decision-making [12], especially in the context of democracy [e.g., 9]. This study explores this emotional engagement through the participants' experiences of images in social media posts, by asking them to reflect on emotions and values. Participants experience emotions and identify values in the material of the offline banners (wool/ yarn) and the crochet process, as well as the messages in the embroidered texts.

The study also addresses the theme of place, currently a central theme across disciplines studying social movements, democracy, data, and urban environments. The crocheted banners at the centre of the research emphasise the campaigns as place-based. In situ, the banners mark the locations of, for example, disputed planning developments, at times when no other physical protests are taking place. The participants identify the banners' attempt to re-claim public space in the face of unpopular commercial developments. These place-based concerns travel onto and across social media within these images.

Marwick and Lewis describe how "far-right groups develop techniques of 'attention hacking' to increase the visibility of their ideas through the strategic use of social media, memes, and bots" [23]. This study provides valuable insights into 'attention hacking', as people are moved and motivated by these banners, even years after encountering them.

\section{ACKNOWLEDGMENTS}

The authors would like to thank participant interviewees and those who contributed photos. This research was funded and encouraged by Edinburgh Napier University's School of Computing.

\section{REFERENCES}

[1] Anne Beaulieu and Adolfo Estalella. 2012. Rethinking research ethics for mediated settings. Information, Communication and Society. 15, 5, (June 2011), 23-42. DOI: 10.1080/1369118X.2010.535838

[2] W. Lance Bennett and Alexandra Segerberg. 2012. The logic of connective action. Digital media and the personalization of contentious politics. Information, Communication \& Society 15, 5 (April 2012), 739-768.

[3] Susan Blackmore. 2000. The Power of Memes. Behaviors and ideas copied from person to person by imitation - memes - may have forced human genes to make us what we are today. Scientific American 283, 4, (Oct. 2000), 2-61.
[4] Pierre Bourdieu. 2000. Pascalian Meditations. Polity Press, Cambridge.

[5] Geoffery Bowker and Susan Leigh Star. 1999. Sorting Things Out: Classification and Its Consequences. MIT Press, California.

[6] danah boyd, d. 2017. Hacking the Attention Economy. Data and Society: Points. Retrieved from

https://points.datasociety.net/hacking-the-attention-economy9fa1daca7a37

[7] Jean Burgess. 2008. All Your Chocolate Rain Are Belong to Us? Viral Video, YouTube, and the Dynamics of Participatory Culture. In Geert Lovink and Sabine Niederer (eds.) Video Vortex Reader: Responses to YouTube (pp. 101-109). Institute of Network Cultures, Amsterdam.

[8] James W. Carey. 1989. Communication as Culture. Essays on Media and Society. Reprint, New York, London: Routledge (1992).

[9] Andrew Chadwick. 2009. Web 2.0: New Challenges for the Study of E-Democracy in an Era of Informational Exuberance. I/S: A Journal of Law and Policy for the Information Society. 5, 1, 9-41.

[10] Sarah Corbett. 2017. How to be a Craftivist: the art of gentle protest. Unbound, London.

[11] Elisabetta Costa. 2016. Social Media in Southeast Turkey. UCL Press, London.

[12] Anton Damasio. 2005 (1994). Descartes Error: Emotion, Reason, and the Human Brain. Penguin, London.

[13] Patrick Davison. 2012. The Language of Internet Memes. In Michael Mandiberg (ed.) The Social Media Reader (pp.120-34). New York University Press, New York.

[14] Richard Dawkins. 2009. The Selfish Gene. 30th Anniversary Issue. Oxford University Press, New York.

[15] Bent Flyvbjerg. 2001. Making Social Science Matter. Why social enquiry fails and how it can succeed again. Translated by S. Sampson. Cambridge University Press, Cambridge.

[16] Homero Gil de Zúñiga, Matthew Barnidge, and Andrés Scherman, 2016. Social Media Social Capital, Offline Social Capital, and Citizenship: Exploring Asymmetrical Social Capital Effects. Political Communication, 34,1, 44-68, DOI: 10.1080/10584609.2016.1227000

[17] Mike Godwin. 1994. Meme, Counter-meme. Wired (1994, January 10th) Retrieved from https://www.wired.com/1994/10/godwin-if-2/

[18] Christian P. Hoffmann and Christoph Lutz 2017. Spiral of Silence 2.0: Political Self-Censorship among Young Facebook Users. In Proceedings of the 8th International Conference on Social Media \& Society (SMSociety '17). ACM.

[19] Henry Jenkins. 2006. Convergence Culture. Where Old and New Media Collide. New York University Press, New York.

[20] Chris Julien. 2015. Bourdieu, Social Capital and Online Interaction. Sociology, 49, 2, 356-373. DOI: 10.1177/0038038514535862

[21] Brian Loader and Dan Mercea 2012. Networking Democracy? Social media innovations in participatory politics. In Brian Loader and Dan Mercea (eds.): Social Media and Democracy. Innovations in participatory politics, (pp.1-10) Routledge, London.

[22] Michael Margolis and David Resnick. 2000. Politics as usual, Sage, New York.

[23] Alice Marwick and Rebecca Lewis. 2017. Media Manipulation and Disinformation Online. Data and Society Retrieved from https://datasociety.net/output/media-manipulation-and-disinfoonline/

[24] Daniel Miller and Jolynna Sinanan. 2017. Visualising Facebook. UCL Press, London.

[25] Daniel Miller, Elisabetta Costa, Nell Haynes, Tom McDonald, Razvan Nicolescu, Jolynna Sinanan, Juliano Spyer, Shriram Venkatraman, and Xinyuan Wang. 2016. How the world changed social media. UCL Press, London.

[26] Ryan Milner. 2013. Pop Polyvocality: Internet Memes, Public Participation, and the Occupy Wall Street Movement. International Journal of Communication 7, 2357-2390.

[27] Kate Miltner. 2015. Memeology Festival 02. From \#Feels to Structure of Feeling: The Challenges of Defining "Meme Culture". 
Culture Digitally. Retrieved from http://culturedigitally.org/2015/10/memeology-festival-02-fromfeels-to-structure-of-feeling-the-challenges-of-defining-memeculture/

[28] Razvan Nicolescu. 2016. Social Media in Southeast Italy, Crafting Ideals. UCL Press, London.

[29] Asaf Nissenbaum and Limor Shifman. 2017. Internet memes as contested cultural capital: The case of 4 chan's /b/ board. New Media \& Society, 19, 4, 483-501.

[30] Zizi Papacharissi 2014. Affective Publics: Sentiment, Technology and Politics. Oxford University Press, New York.

[31] Katy Pearce. 2015. Memeology Festival 07. Memetic Disparaging Dissent: Memes Against the Oppressor in Azerbaijan. Culture Digitally. Retrieved from http://culturedigitally.org/2015/11/memeology-festival-07-memeticdisparaging-dissent-memes-against-the-oppressor-in-azerbaijan/

[32] Limor Shifman. 2013. Memes in Digital Culture. MIT Press, Cambridge, MA, USA.

[33] Liesbet Van Zoonen, Farida Vis, and Sabina Mihelj. 2010. Performing citizenship on YouTube: activism, satire and online debate around the anti-Islam video Fitna. Critical Discourse Studies, 7, 4, 249-262.

[34] Claire Wardle and Hossein Derakhshan 2017. Information Disorder: Toward an interdisciplinary framework for research and policymaking. Shorstein Center and Council of Europe. Retrieved from https://shorensteincenter.org/information-disorder-frameworkfor-research-and-policymaking/

[35] Wool against Weapons. Retrieved from http://www.woolagainstweapons.co.uk/

[36] Scott Wright. 2012. From 'third place' to 'Third Space': everyday political talk in non-political online spaces. Javnost, 19, 3, 5-20.

\section{APPENDIX: SEMI-STRUCTURED INTERVIEW PROTOCOL}

Note that the printed protocol also included potential prompts for each question.

1. Have you seen the banner offline? And/or any others like it?

2. What made you post/re-post/ retweet the image? Do you agree with the statement?

3. Were you aware of the campaign/ issue before seeing the image? Did you have other involvement in the campaign? Before? Afterwards? Online/offline? Are you aware of similar banners (e.g. in [this city])? Have you seen images of the other banners on social media?

4. Can you tell me about any emotions you have associated with the banner?

5. Or any values? Are these values/ emotions from the photo or the offline banner?

6. What would you say the banner is made of?

7. Do you know who created the banner? If so, is this someone who you know offline?

8. Do you think the banners' creators use social media?

9. Do you often post or retweet political posts/ images?

10. Do you know the term meme? If so, would you call this a meme? 